\title{
The Trajectory of Tribal Development Practice: The Case of Muthuvan Community in Kerala
}

\author{
Pradeep Kumar K $S^{* 1}$
}

\section{Abstract}

Tribal development in Kerala has now reached a perplexing situation due to the failure of the state in ensuring the inclusive well-being of the members of tribal communities. This is also true with regard to sustaining their age-old ways of life and living circumstances. A comprehensive analysis of the tribal living conditions in the state is essential to get a clear idea of the 'developmental issues and concerns' and to arrive at clear ways of resolving them. Several tribal communities or a majority of their hamlets have already shifted or are in the process of shifting to the new living circumstances. Not being a smooth shift, involves serious struggles for survival with drastic shifts being demanded in the modes livelihood, patterns of living, belief systems etc. This has brought the traditional ways of tribal existence in the state under serious challenge with old models of coexistence and environment-based living nearly put to an end. Amidst this state of affairs, it is truly a fascinating scene to watch that in a few hamlets of certain tribal communities, such as Muthuvans in Idukki district and its adjoining areas in Kerala, the elements of traditional life still survive

\footnotetext{
* Department of KIRTADS, Kerala, India; kspradeep76@gmail.com
} 
despite their intermixture with the mainstream population. The paper draws from field observations and attempts to understand the trajectory of tribal existences in Kerala State. The move from tradition to the present day modernity is closely analysed here, with or without the academic rigour, in order to present the reader with some dairy notes that could be useful to comprehend the magnitude of the change and the ensuing struggles.

Keywords: Tradition and modernity, Social change, Scheduled Tribes, Muthuvans, Shifting cultivation, Hamlet or kudi

\section{Introduction}

This is not intended to be an academic paper as much as it is suggested to be read as providing some observations from my own field experiences. However, the observations are not about the lifestyles or practices of the tribes whom I attempt to describe below, or it is not just that. I try to make a summary of the shifts that have taken place in the lifestyles and surroundings of the Muthuvans settled in the different parts of Kerala. Thus it combines the socio-economic with elements of culture and society against the larger questions/sequences of social change.

The geographical surroundings, livelihood scenario, a way of life, and socio-cultural features of the 37 Scheduled Tribe (ST) communities of the State of Kerala are at varying levels even though their main habitation area is along the Western Ghats mountain ranges that form the hilly eastern boundary of the State. The disparities can be seen between the communities and within a community. For instance, only a few hamlets of the Muthuvan of Idukki and Ernakulam districts ${ }^{2}$ and that of the Kurumbar of Palakkad district are now doing shifting cultivation for a living while most of the members of the Kurichiyan, Maraty, Ulladan, Uraly, Mavilan, Muthvan, Mannan, Mullu Kuruman, Karimpalan and Malai Arayan are engaged in settled cultivation. Communities like Cholanaiken ${ }^{3}$ of Malappuram district and many among the Kadar, Kattunayakan ${ }^{4}$, and Malai Pandaram communities are even nowadays depending exclusively on Non-Wood Forest Produce (NWFP) collection as a major source of livelihood. Wage labour is 
the major occupation of the Paniyan, Adiyan, Aranadan, Mala Vettuvan, and Mala Vedan communities.

The State and Central Governments has initiated a number of measures including the pronouncement of a number of legislation that aims to protect and promote the interest of the tribal communities of the country. However, many such steps are not found to be effective in addressing most of the contemporary issues faced by the ST communities of the State of Kerala. The delayed and poor implementation of many Acts, such as 'The Scheduled Tribals and Traditional Forest Dwellers (Recognition of Forest Rights) Act, 2006', 'The Kerala Scheduled Tribes (Restriction on Transfer of Lands and Restoration of Alienated Lands) Act, 1975', 'The Scheduled Castes and Tribes (Prevention of Atrocities) Act, 1989', etc., which addresses many current issues of the ST communities of the State, is also a major set back in improving the socio-cultural, economic, educational and political attainments of the ST communities of the State. It is in this context that the Kerala Institute for Research Training and Development Studies of the Scheduled Castes and Scheduled Tribes (KIRTADS) initiated a research study in 2014 to look in to the impact of recent legislation on the ST communities of the State of Kerala in the context of the Muthuvan and Palliyan tribes in Idukki district of the State. A number of hamlets of the above mentioned tribal communities were visited as part of the study and the following account is an attempt to analyse the development path of the tribal communities of the State from the traditional to the present settings out of the persisting life situations of the Muthuvan settlements in the Marayoor, Edamalakudi and Mankulam Panchayaths of Idukki district.

\section{Tribal Development Scenario in Kerala: A Brief Appraisal}

The concept of tribal development has been viewed in a number of ways from the perspective of various disciplines and the scholars. Simply one can state tribal development as a positive change that happens to the tribal communities. Anyhow one of the main postulates of tribal development is to support the tribes to become part of the mainstream. Vaid (2004:4) describes tribal development as "change in the desired direction within stipulated time". 
However, for the scope of this paper, the concept of tribal development is viewed as the sum total of the socio-cultural, economic, political and behavioural changes that improve the wellbeing of the tribal communities. Chathukulam and John, (2006:197) states, while commenting on the tribal development issues of the State of Kerala, that "The tribes remain showpieces for development planners and a source of easy money for corrupt officials". In most of the cases, the development projects were not successful in producing the desired improvement to the way of life of the tribal communities mostly because of the negligence in taking into account of the ground level realities of the tribal settlements.

Traditionally forest ecosystem is the main habitation area of the Scheduled Tribe communities of the State. They have been doing shifting cultivation, raise dwelling out of the locally available materials, and develop distinct beliefs, practices, and elaborate systems of social organizations, all in tune with nature. In short a life of self-sufficiency and sustainability. Nevertheless, in the course of time, most of their traditional means of sustainable living were taken away by mainstream population and they were forced to move into the interior forest areas, most of which now fall under the category of Wild Life Sanctuaries and National Parks. Nowadays, many ST communities of the State have lost their major sources of traditional means of living and many aspects of sociocultural life mainly out of their contact with the 'other people'. Hence, at present, it is very difficult to find a so-called 'traditional life', 'co-existence of traditional and changed life', and 'life having little elements of tradition' in many tribal communities of the State. Muthvan community of Idukki district is an exception to this. That is why the Muthvan community has been selected to analyse the route of tribal development in Kerala. The following is an attempt to trace the trajectory of life of the tribal communities in Kerala State from the 'traditional' to the 'present' by analysing the contemporary live situations of some of the hamlets of the Muthuvan community. 


\section{The Muthuvan Community of Kerala}

The major concentration of the Muthuvan community is in the Idukki district followed by Ernakulam and Thrissur districts. The community is mainly distributed in 110 settlements and their population in the state is recorded as 12305 (6273 Males and 6032 Females) $)^{5}$. Most of their settlements are either within or at the fringe areas of the forests that are variously categorised. Marayoor, Kanthaloor, Edamalakudi6, Adimali, and Mankulam Grama Panchayaths in Idukki district and Kuttampuzha Grama Panchayath in Ernakulam district are the major habitation areas of the community. However, their way of life and socioenvironmental conditions in the above-mentioned areas vary and a look at the contrasting scenario of the community's 'traditional' and 'changed life' mentioned above would give a clear picture about the general trend of the development practices among the Scheduled Tribes communities in Kerala.

\section{Traditional Life at the Contemporary Scenario}

Vellakkal kudi (hamlet) in Marayoor Grama Panchayath is around 15 kilometres from the Marayoor town and is situated within the Chinnar Wild Life Sanctuary. There is a mud road to the kudi but only I K.M road is in good condition and the rest of which is very dilapidated. Hardly any vehicle goes to the kudi and the outsiders are not permitted to visit the $k u d i$ as it is situated in the dense areas of the Sanctuary. The kudi is situated at high mountain slope and is around 1500 feet above sea level. They practice shifting cultivation and cultivate a wide variety of food grains that are used only for consumption. Ragi (Little Millet), Maize (Sorghum), Thina (Italian Millet), Varagu, Chama Rice, Tomato, Carrot, Sweet Potato, Potato, Cheeni Vala, Toppi, Mocha, etc. are the important food crops cultivated by the members of the kudi. Almost all the crops are cultivated in the same field, side by side, and many of the crops provide yield at different periods in a year. Around 50 families are there in the kudi and they do shifting cultivation around 2000 acres of land. Agricultural operations are done together by all the kudi members. However, there is an understanding among the community members that each family will take yield only from a particular portion of the agricultural land. Thus, one can assume that there is only a vague concept of family property among the 
members of the community. In that sense, each family has around 50-100 acres of land under their custody. However, there is no clear-cut demarcation between the lands of one family from the other. The slope of one side of the hill belongs to one family, while next to another. The entire cultivation is depended on rainwater. They cut the shrubs and burn them during March -April, and dig the soil and start cultivation by June-July. They never use chemical fertilisers; charcoal and ash give the necessary fertility to the soil. The same land is not cultivated in subsequent years and the cultivation resumes in a particular land only after a gap of seven years. Yield from shifting cultivation is enough to meet the food needs of the community members. They never sell the excess grains at the market for cash rather all the members of the community are ready to give the excess food grains in their custody to those in need.

Their houses are built out of the locally available materials. Wooden poles, mud, and grass are the only essential raw materials for building a residential structure. Some of them use tin/asbestos sheets for thatching houses and use cement for plastering the walls owing to their contact with the mainstream society. They erect large flat structures made of bamboo, wooden branches, grass, etc., close to the mud wall of the houses for protecting their houses from the fast-moving wind and rain. Almost all the works in the kudi, including the house construction, are done with the participation of all members of the kudi. And the society is also so organized to carry out the communitarian way of life. There are separate savadies (dormitories) in the kudi for the males and females, where the younger members before marriage and old people spend the night. And there are separate leaders among the male and female youths and all the youths of the kudi are under their command. Kani and Thalaivar look after the entire affairs of the kudi. A Multi-Grade Learning Centre (MGLC) and an Anganawadi ${ }^{7}$ are working in the hamlet for the education of the children. Many children of the hamlet are known to pursue Upper Primary and High School Education at the nearby schools by staying at the hostels run by ST Department. They have a high self-esteem and consider themselves as superior to other communities in the area, and follow strict rules of endogamy. All these reveal that the Muthuvans in Vellakal Kudi are self-sufficient in almost all aspects, their culture, belief systems, 80 
and agricultural practices are all intact. And they represent the present day traditional, comfortable living circumstances of an ST community of the State.

\section{The Changing Life at the Contemporary Scenario}

Edamalakudi Panchayath encompasses 28 kudies of the Muthuvan community. All the kudies are in the forest area. There is no vehicle road facility to the kudies (hamlets). One has to walk 10 to 15 kilometres from the nearby vehicle road situated at Pettimudi, Nallamala (in Tamil Nadu State), and Anakulam areas. They are used to rice and other food items of the mainstream. Puthukudi, (now popularly known as society kudi) and Parapayar kudi have societies/shops run with the assistance of Government. The Panchayat building is situated at Puthukudi, while its office works from Devikulam, Munnar. The kudi also has a Lower Primary School and a Family Welfare Sub-Centre of the Health Department. Many kudies do shifting cultivation only to a low extent. Cardamom is the main crop of the people. Most of the traditional shifting cultivated areas of the community are now replaced with cardamom fields. It is known that the cardamom plantations were started at the initiatives of the forest Department and later supported by the Scheduled Tribes Development Department (STDD). However, as the community members became fascinated with the upcoming cardamom plantation, where money motive and family ownership got prominence, shifting cultivation became ceased in many traditionally shifting cultivated lands as the cultivation practice lost significance in the changed situations. And at a certain point of time, many such lands were taken over by the Forest Department, and thereby the landholdings of the members of the community became diminished.

The fall in the price of cardamom at certain years coupled with crop failure compelled the members of certain kudies, such as Mulakuthara, Keezhpatham, and Nenmanal, to turn to other cash crops such as areca, pepper, coffee, rubber, etc., for a living. It is known that usually community members borrowed money from the businessmen of the nearby markets so as to meet the cost of seedlings, labour, fertilizers etc. in their quest to cultivate cash crops and as a result of poor harvest and fall in price many a time 
they have to give the entire yield to them for repaying the debt. This in turn put the community members in financial crisis, and they used to sell their land holdings to adjust the financial situation. The shift towards the cash crops make the community more individualised and many features of the traditional mechanism of social organization, such as savadi, became vanished from the kudies.

\section{The Changed Life at the Present Scenario}

Nagamala kudi (pseudonym) in Adimali Panchayath is around 15 kilometres from the nearby town Mankulam. 10 kilometres journey through mud road that goes through the forest has an abundance of bamboo brings one to kudi. The old Aluwa-Munnar road goes through the kudi. The kudi is not entirely cut off from the mainstream life, but it is a part of it. There are around 250 families in the kudi. Rubber, Plantain, Areca, Tapioca, Coconut, etc. are the major crops of the kudi. They are not practising shifting cultivation. The land holding of the families varies from 10 cents to 10 acres. The communitarian life has been lost. Each family has to look after their own affairs. Some of them give their land on lease; some sold a portion of their land to other members of the community as well as to members of other ST communities such as Malai Araya. Also, many of them depend on bamboo cutting for the industries, which gives them the wage labour available in the area for a living. Traditional beliefs and practices are changing very fast; around 50 families have embraced Christianity. Traditional savadi is out of existence. Many have become addicted to alcohol. Traditional houses are replaced with concrete structures. These are some of the major changes noticed among the community members.

The policies of the government and the interference of the public at large to their living have altered their traditional ways of living to a greater extent. Only those interventions that help the overall wellbeing of the community in total are good. In that sense the path of Vellakal kudi is right and sustainable since they have retained their traditional shifting cultivation practices that ensures food security for all, and many aspects of their age-old communitarian way of life, which revolves around a strong group feeling and social security for all, even though they have accepted many aspects of 
the so-called mainstream life. The State and non-State agencies have been a number of development programs and policies to bring the tribal communities into mainstream life. Many a time the development and interventions so implemented and contact with the wider society have changed the tribal way of life to a large extent. However, over the years, many tribal communities the State are in the course of transformation, i.e., life, mentioned above, whereas many others have already transformed totally, i.e., reached 'life' stated above, in terms of their communitarian patterns of life systems, sources of livelihood, food culture, health and security etc. Thus, the development strategies adopted by the state do not in anyway ensure a comfortable life for the members of the tribal communities in general.

This is because the discourses 8 that govern the way of life of the tribal communities, in general, are quite different from those of the mainstream society. The mainstream discourses are those that are constituted in the interplay of modern power which in turn controls and regulates communities living in its margins, including the tribes. The worldviews and perspectives of the tribal communities including Muthuvan of Kerala are quite different from that of the 'other people', and they are at the opposing ends with conflicting features (Pradeep, 2016:52-57). In fact, the increased interaction between the tribal people and those of the 'elite mainstream' compel the former to accept the many features of the worldview of the later, which in turn resulted in the extinction of many traditional perspectives of tribal life. It leads to the end of many sustainable sources of the life of the tribal communities among other things.

The mainstream society celebrates the presence of tribal communities while at the same time portray them as "',underdeveloped', 'uncivilised' and not accept the 'development fruits' the State. In fact, only those communities/those members of tribal communities, who can actively participate in the discursive practices of the State can adapt to the dominant discourses that govern the life of the majority people and thereby able to lead a comfortable life. 


\section{Conclusion}

The 'economic, social and cultural capital'", assertive enough to actively engage with the dominant, mainstream discourses of the society. This is mainly because of the persistence of a distorted account of the socio-cultural characteristics and the ways of life of the tribal communities nourished by the statist commands created by the elite strata of the society. The formulation of 'Criminal Tribe' category in India by the British colonial Government in 1871 by attributing 'criminal behaviour' upon some of the nomadic communities in the country had resulted in the enforcement of a wide range of 'social stigma' on them ${ }^{10}$ is an instance of the abovementioned observation. Thus, some conscious efforts are required to acknowledge and enhance the 'economic, social and cultural capital' of the communities so that they can become active participants of the dominant discourses of the society as well as an integral part of the society at large. For that, a knowledge system that celebrates and supports the uniqueness and diversity of tribal culture has to be created.

\section{References}

Ahmed, V. M., (2016). Thozhil, Kuttakrithyam: Jeevitham (Malayalam) (Work, Criminality: Life). Mathrubhoomi Weekly. 94 (4), 20-35.

Bhanu, B. A. (1989). The Cholanaickan of Kerala (No. 72). Anthropological Survey of India, Ministry of Human Resource Development, Department of Culture, Government of India.

Barry, P. (2012). Beginning Theory: An Introduction to Literary and Cultural Theory. New Delhi: Viva Books Pvt. Limited.

Callewaert, S. (2000). Pierre Bourdieu. In, H. Anderson and L. B. Kasperson (Eds). Classical and Modern Social Theory. Massachusetts: Blackwell.

Chathukulam, J. and John, M. S. (2006). Issues in Tribal Development: The Recent Experience of Kerala. In, G. C. Rath. Tribal Development in India. New Delhi: Sage Publications.

Kumar, P. K. S. (2016). Marunna Mannu Sankalppam: Muthuvan Gotra Janathayilude (Malayalam) (Changing Perspectives on Soil: In the Context of the Muthuvan Tribal Community). In Seethal V.S (Ed.). Mannakam, Mannum Samskaravum (Malayalam) (Mannakam, Soil and Culture)

Vaid, K. N. (2004). Who Cares for Tribal Development. New Delhi: Mittal Publications. 
1 The paper is based more on direct field experience and the author is working as a Deputy Director, Department of KIRTADS, Kerala, India; the opinion expressed in the paper belongs exclusively to the author and the Department has no responsibility for the same.

2 Muthuvan of Malappuram and Kozhikode districts is an entirely different community and are locally known as Malamuthans. They have no socio-cultural similarities with the Muthuvan community of Idukki and Ernakulam districts.

3 The Cholanaicken community is referred by some scholars as the 'cave men' of Kerala. For more see Bhanu (1989).

4 Cholanaicken, Kattunayakan, Koraga, Kadar, and Kurumbar are coming under the Particularly Vulnerable Tribal Groups (PTGs) category of the State. The categorization was formed in the year 1975.

5 Survey conducted by KILA and the Scheduled Tribes Development Department in 2008.

${ }^{6}$ Edamalakudi is the only tribal Panchayath in Kerala, where only the members of Muthuvan community are residing.

7 An institution meant for children below five years, mothers and adolescent girls under the Social Justice Department of the State.

8 Discourse in Foucault's terminology is the 'whole 'mental set' and ideology that encloses the thinking of all the members of a given society' (Barry, 2012:170).

9 In Bourdieu's terms the concept of capital denotes "the material and socio-cultural inheritance which forms the basis on which various social agents act in various fields in social space", (Callewaert, 2000:309).

10 For more see Ahmed, (2016: 20-35). 